\title{
Green Mussel, Perna viridis, Farming in Kerala, India - Technology Diffusion Process and Socioeconomic Impacts
}

\author{
V. KRIPA \\ Research Centre of Central Marine Fisheries Research Institute, West Hill, \\ Calicut 673005 Kerala, India \\ K. S. MOHAMED 1 \\ Central Marine Fisheries Research Institute, PO Box 1603, Cochin 682018 Kerala, India
}

\begin{abstract}
The technology diffusion process of green mussel, Perna viridis, farming in Kerala, India, was studied by analyzing the adoption pattern, socioeconomic profile of mussel farmers, differences in farming methods, profit variations, development of trade and downstream industries, and the social factors responsible for the growth of this new industry. The farming practice has been adopted by villagers from 1996, and because of its rapid growth, India has risen to one among the top 10 farmed mussel producing nations in Asia, with an annual production of 10,060 tonnes, worth \$US1.79 million at farm-gate level. Three types of farm ownerships were observed: individual ownership (IND), family ownership (FAM), and ownerships by self-help groups (SHG). The adoption curves are such that there were only a few adopters initially followed by an increasing rate of adoption in the subsequent years because of the demonstration effect. The study indicated the deep-rooted "risk aversion" attitude widely prevalent among technology adopters. Age could not be significantly related to technology adoption, while education and occupation of the respondents significantly $(P<0.05)$ influenced the technology adoption process. The biggest outcome of mussel farming in Kerala was the empowerment of women with $87 \%$ of the SHG farms owned by women. The successful diffusion of mussel farming is the result of a combination of factors, chiefly, the availability of suitable water bodies; high rate of education; proximity of mussel markets and high degree of mussel consumption in the area; and a unique synergy between technology developers, promoters, and credit advancers. This development scenario can work as a role model for developing nations.
\end{abstract}

Many countries practice mussel farming, and according to recent estimates, the global production has increased by 22.8 times from 0.07 million tonnes in 1950 to 1.58 million tonnes in 2003 (FAO 2003). In India, the technology for farming the green mussel, Perna viridis, was developed during 1970s and was subsequently tested for feasibility at various locations along the country's southeast and southwest coasts by Central Marine Fisheries Research Institute (CMFRI) (Qasim et al. 1977; Appukuttan 1980; Kuriakose 1980; Rangarajan and Narasimham 1980). However, the technology was not adopted by fishers because of risks associated with sea farming such as poaching, weatherrelated loss of farm structures from the sea, and

\footnotetext{
${ }^{1}$ Corresponding author.
}

lack of awareness. Adoption of this aquaculture practice by coastal villagers began only in 1996 when it was field tested in shallow backwaters of Kerala, a maritime state along the southwest coast of India (Appukuttan et al. 2000). This shift to calm waters increased the security of farm structures.

Although the technology for mussel farming has been demonstrated in several locations within Kerala State and in different maritime States (Rivonker et al. 1993; Sreenivasan et al. 1996; Natarajan et al. 1997; Mohamed et al. 1998; Rajagopal et al. 1998; Sasikumar et al. 2000), the diffusion of the technology was predominantly in northern districts of Kerala. Several reasons such as fast growth of mussels because of favorable hydrological and geoclimatic conditions (Velayudhan et al. 2000), availability of seed from nearby coastal areas (Appukuttan 
et al. 2001), and availability of loans and subsidies from banks and development agencies (Asokan et al. 2001; Vipinkumar et al. 2001) have been identified as contributory factors for this development. Further, a traditional mussel fishery (annual harvests from the wild are approximately 15,000 tonnes) exists along the northern Kerala coast, which serves to indicate the popularity of mussels in the local diet. A very close network between the technology developers and promoters, villagers, and local village governing bodies has been identified as essential for motivating farmers to adopt a new aquaculture technology (Kripa et al. 2004).

Even within Kerala State, there are areas where the adoption levels are high when compared to certain villages where the adoption level has not progressed beyond the primary adopters. Although nearly a decade has passed since the initiation of mussel farming in coastal villages of Kerala, the rationale behind the growth of mussel farming industry and its sustained development as a village-based smallscale group farming enterprise in India has not been critically evaluated. Some questions which have been frequently asked are: Why is this technology so popular in the coastal villages of Kerala? What are the main reasons for its sustained adoption year after year? How has this technology helped in women's empowerment and their economic independence?

The main objectives of the study are to understand the prevailing adoption pattern, socioeconomic profile of mussel farmers, and the regional difference in farming methods and related profit variations, development of allied trade and downstream industries, and the technological and social factors responsible for the growth of this new industry. The study also aimed at identifying the role of women in mussel farming. Also, it is hoped that the evaluation of the success in adoption of this technology in Kerala can act as a model for promoting mussel farming in similar sociological and geoclimatic regions in developing nations.

\section{Materials and Methods}

Mussels are farmed mainly by the off-bottom method using trestles (known as racks in India) in six coastal districts of Kerala (Fig. 1;

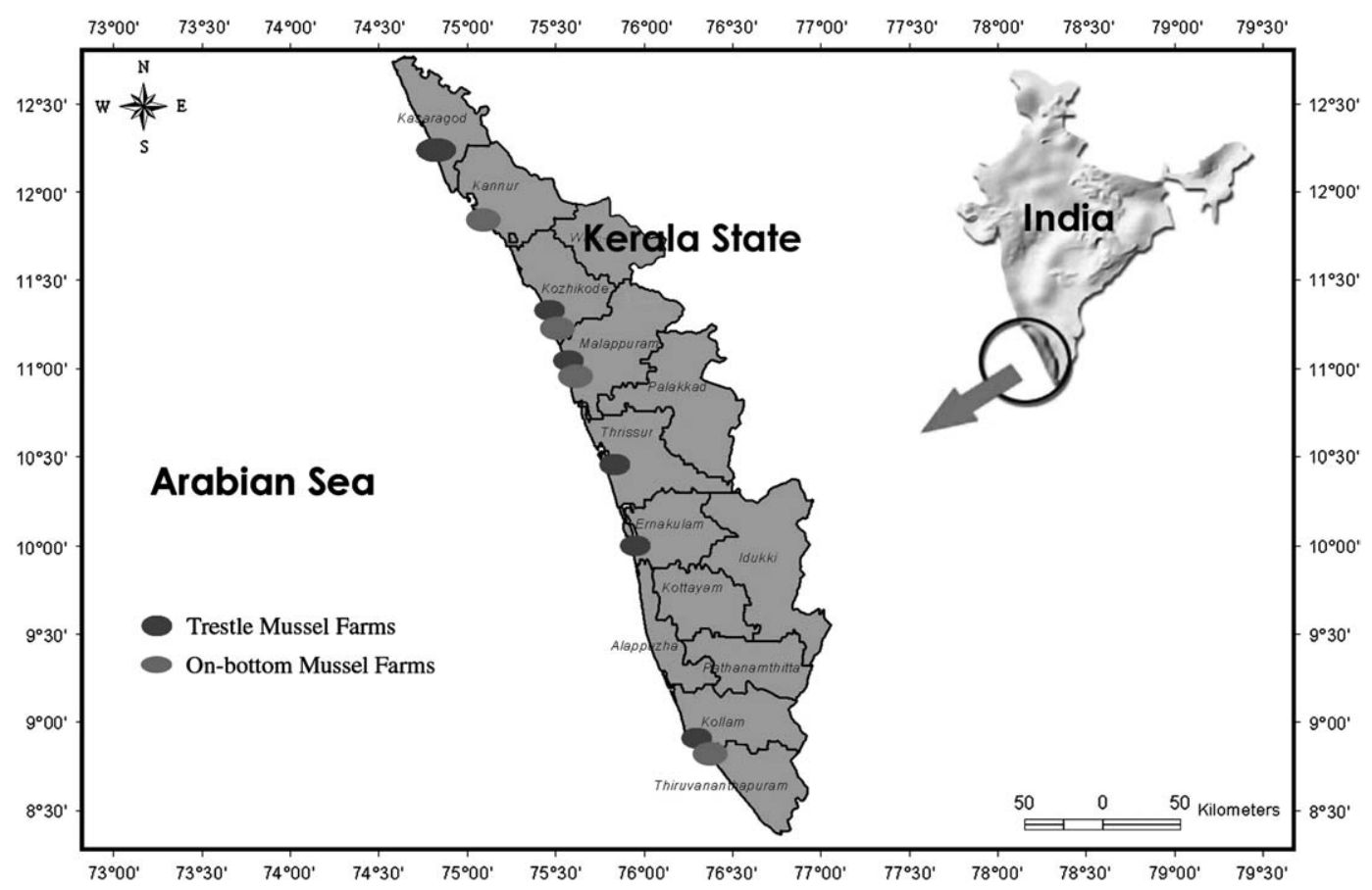

FIGURE 1. Map showing locations of trestle and on-bottom mussel farms in Kerala State, India. 
$\left.8^{\circ} 30^{\prime}-12^{\circ} 30^{\prime} \mathrm{N}, 7^{\circ} 30^{\prime}-77^{\circ} 00^{\prime} \mathrm{E}\right)$. Apart from this, in certain regions, seed mussels are just sown on the substrate (on-bottom) and farmed. This study, conducted during 2005-2006, is restricted to North Kerala in three coastal districts, namely, Kasargod, Kozhikode, and Malappuram which are the major mussel farming regions, contributing to nearly $99.5 \%$ of the farmed production in the country. Other districts (Kannur, Thrissur, Ernakulam, and Kollam) have negligible production and therefore were not included in the study. Only mussel farmers with trestles were selected as respondents because on-bottom farming is not an organized and consistent farming practice.

Data on estimates of farmed mussel production, number of adoptees, and extent of loans and subsidies from state development agencies were derived from the records of district and village administrative offices and the Green Mussel Farmers Society at Kasargod. The main agencies which extended financial support to mussel farmers were the North Malabar Gramin Bank (NMGB), the Agency for Aquaculture Development in Kerala (ADAK), Brackishwater Fish Farmers Development Agency (BFFDA), village cooperative societies, and the village governing councils (Panchayat). A schedule was designed for collecting data on socioeconomic and demographic profile of the farmers such as age, educational background, occupation, farming methods, and related aspects such as sourcing of inputs for farming, sharing of responsibilities, production, hired labor, constraints, source of finance, repayment of financial liabilities, utilization of profit, markets for produce, and method of marketing. All the villages practicing mussel farming in Kasargod, Kozhikode, and Malappuram were covered, and the schedule was distributed based on a random sampling design so as to ensure more than $50 \%$ coverage. The number of respondents was 352 from Kasargod, 60 from Kozhikode, and 115 from Malappuram.

To compare the economic performance of mussel farms in different regions, information on capital investment, annual fixed costs, interest rates, depreciation, operating cost, yield, and sale price was collected using the same schedule. Financial subsidies were not consid- ered in this analysis. From this data, the total cost of production, gross returns, net operating income, net cash return, break-even price, capital recovery factor $(\mathrm{CRF}=$ net cash return/ capital investment) were computed. A key economic indicator, rate of return (RR), was estimated separately for Kasargod, Kozhikode, and Malappuram using the following inputs:

$$
\mathrm{RR}=\frac{\text { net cash return }+ \text { interest }}{\text { capital investment }} \times 100
$$

From the economic data, the quantity and value of the raw materials used, such as mussel seed, bamboo poles, coir rope, degradable cloth, and so forth, for the crop period 2005-2006 were estimated for each district for assessing the spread and worth of the downstream industries supporting mussel farming.

The information on the number of labor-days of employment generated in other nonfarm regions such as seed collection and transporting was gathered by directly visiting the sites and through inquiries with the fishers and agents involved. The market channels were also identified, and details on the main markets were collected.

To identify and quantify the benefits from farming, the respondents were queried on repayment of financial liabilities and utilization of profit for personal needs. Motivational factors for adoption of technology were also included in the schedule. The district-wise and genderwise variables measured were arranged into a frequency table and subjected to chi-square test to identify the significant differences at 0.05 level and the main sources of variation (Sokal and Rohlf 1995). Region-wise adoption curves were fitted to analyze the speed of adoption.

\section{Results}

\section{Mussel Production and Its Value}

Mussels are farmed in trestles in the estuaries and backwaters of Kasargod, Kozhikode, Malappuram, Thrissur, Ernakulam, and Kollam (Fig. 1) districts of Kerala, and the production from trestles has contributed $81 \%$ (8140 tonnes) to the total farmed mussel production during the 
period 2005-2006. The annual production of farmed mussels has shown a gradual increase from 1997 and it was steep particularly from 2003 (Fig. 2). On-bottom farming, which is a custom of simply relaying of seed mussels with low inputs, contributed 19\% (1920 tonnes) to the production. The value of the mussel produced is estimated as \$US1.79 million on the basis of farm-gate prices during the period 2005-2006.

The total area utilized for trestle farming in 2005-2006 was estimated as 14.14 ha, and onbottom farming was done in 11.17 ha in the state mainly at Kozhikode and Malappuram districts. The average productivity for trestle method was estimated as 564.9 tonnes/ha, while for on-bottom method, it was 171.9 tonnes/ha. However, there were regional differences in productivity, with high values in Kasargod and comparatively low values in Kozhikode and Malappuram.

\section{Farm Ownership}

In Kasargod district, mussel farming first began as a small-scale activity consequent to the demonstrations by the technology developer and promoter, CMFRI in two villages, in 1996. Mussel production through trestles in Malappuram district began in 1998-1999 and in Kozhikode district in 2002-2003 consequent to similar demonstrations in 1998 and 2002, respectively. Three types of ownerships were observed: individual ownership (IND), family ownership (FAM), and ownerships by self-help groups (SHG) (Fig. 2).

For IND, individuals representing a single person or a single family owns mussel farms, and presently, 559 farms (forming 63.9\% of the total farms) are of this type. Such farms were observed in all the three districts. Maximum numbers of individual-owned farms are located in Kasargod (372 farms forming 62.6\%). At Kozhikode and Malappuram, IND farms formed 70 and $65 \%$ of the total farms, respectively.

FAM farms had combined ownerships of two to three families related to each other. In some instances, all the family members lived in the same house or in separate adjacent houses in the same village. The farm is a joint property and one member is the main decision maker.

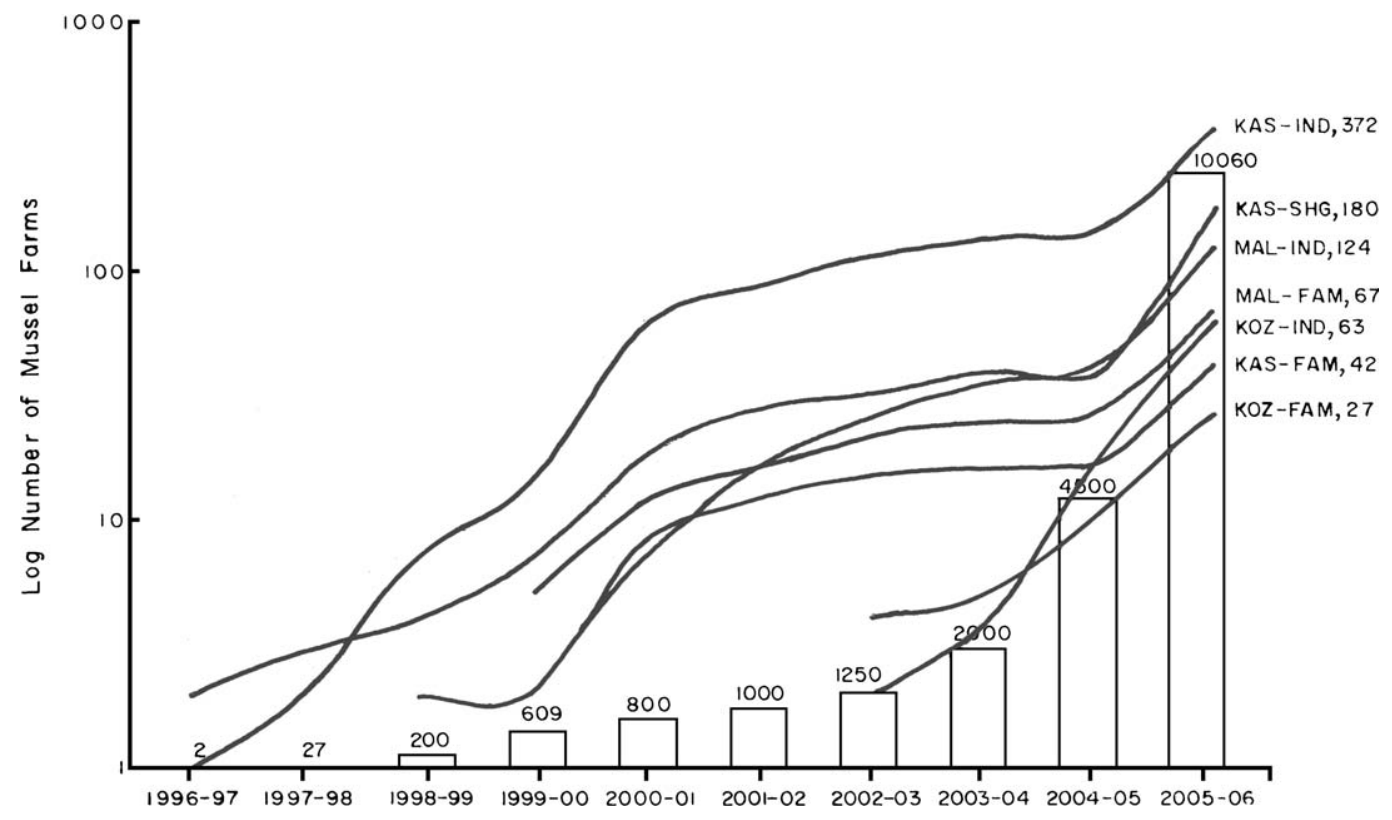

FIGURE 2. Adoption curves of different ownership mussel farms (individual ownership - IND; family ownership - FAM; and ownerships by self-help groups - SHG) in Kasargod (KAS), Kozhikode (KOZ), and Malappuram (MAL) districts. Bar chart shows the estimated annual farmed mussel production in tonnes. 
Such farms were found in all the three districts. In general, $15.5 \%$ of the farms were family owned. However, in Kasargod, $7.1 \%$ of the farms belonged to this category, whereas at Kozhikode and Malappuram, they formed 30.3 and $35 \%$, respectively.

A third type of ownership, SHG farms, was observed in Kasargod district only. Seventeen to 20 individuals of different households, usually not related to each other, but with almost similar economic status, and who are residents of the same village, formed SHG and they owned and operated mussel farms. Such SHGowned farms were observed only in Kasargod. Each SHG is controlled by an executive committee with a President, Secretary, Treasurer, and five to six executive members. These groups are expected to follow a specific working pattern such as regular group meetings, analyzing the income and expenditures, and so forth. Such a group is entitled for certain benefits from the local state administration for effectively utilizing the local resources. They avail loans from banks, promptly repay the loan, and shared the profit. During the period 2005-2006, there were 180 SHGs in Kasargod district, and the villagers of Kozhikode and Malappuram were also planning to form SHG units in the ensuing season.

\section{Motivation for Technology Adoption}

In all the three districts, the first set of farms was set up based on the motivation from the training programs and demonstrations of mussel farming by CMFRI and other technology promoters. Subsequently, the number of farms increased on account of success of mussel farms in the neighborhood. In Kasargod, maximum numbers of farmers $(67 \%)$ were motivated by the successful mussel farming activities in the neighborhood, and $30 \%$ of the farms were set up because of demonstration effect (Fig. 3). In Kozhikode and Malappuram, $88 \%$ and $66 \%$ of the farmers, respectively, were motivated by the training program of CMFRI. A very significant role was played by the financing institutions. The loans and subsidies by organizations especially the NMGB and the cooperative societies have supported the development of mussel farming in Kasargod.

The financial assistance schemes of technology promoters, like ADAK and BFFDA, prompted $12 \%$ of the farmers in Kozhikode to take up mussel farming, while at Kasargod and Malappuram, their influence was negligible. At Malappuram, $30 \%$ of the mussel farmers started this income-generating enterprise seeing the success of neighbors who owned mussel farms.

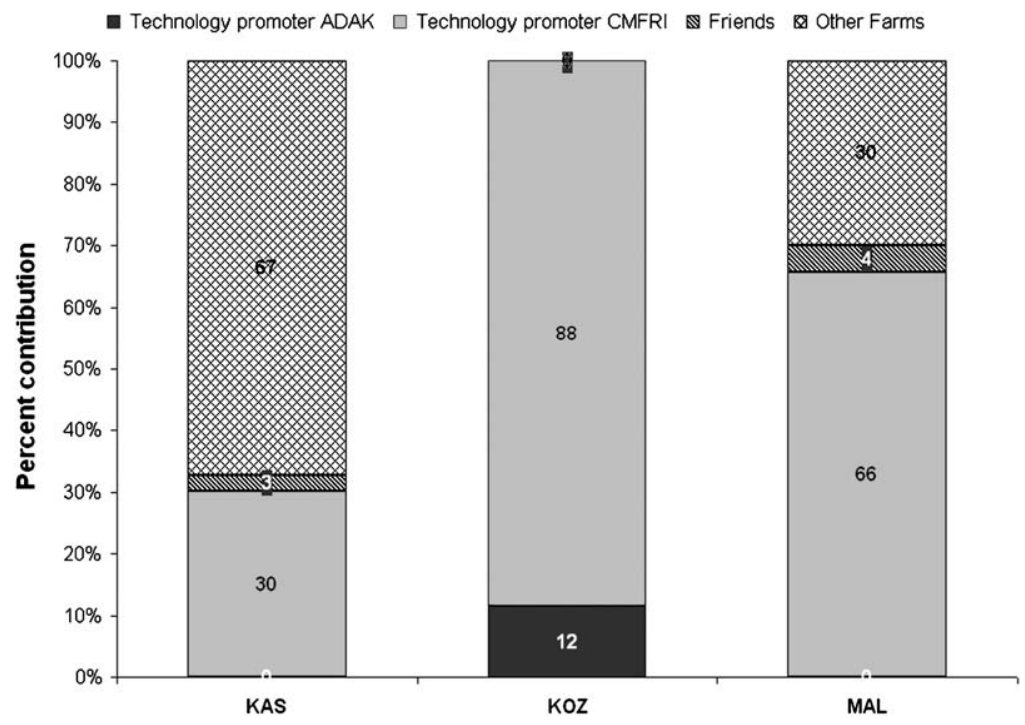

FIGURE 3. Factors responsible for motivating respondents to take up mussel farming in Kasargod (KAS), Kozhikode (KOZ), and Malappuram (MAL) districts. 
However, the pace of growth was low at Kozhikode than the other two districts.

\section{Demographic Profile of Mussel Farmers}

Age did not significantly influence adoption of mussel farming $(P>0.05)$. More than 50\% of mussel farmers in all three districts except those with family-owned farms in Kasargod were in the 30-50 age group (Table 1). Number of farmers in $<30$ age group were low at Kasargod and Malappuram and completely absent in Kozhikode. However, the number of SHG farmers were comparatively more $(21 \%)$ in the younger age group $(<30)$. Between 40 and $50 \%$ of the farmers with FAM farms at Kasargod and Kozhikode were in the $>50$ age group. However Malappuram FAM farms were operated mostly (77\%) by the $30-50$ age group, and only $18 \%$ were $>50$ in age.

More than $80 \%$ of the mussel farmers were literate and had formal school education, and educational background significantly influenced technology adoption $(P<0.05)$. The key factors in the significance were the presence of farmers educated to college level and of laborers both at Malappuram (Table 1). However, in Kasargod, about $17 \%$ of the farmers with FAM farms and $14 \%$ of SHG members have had no formal education. At Kozhikode and Malappuram, less than $10 \%$ of the farmers had not attended school. While only $4-10 \%$ of the farm- ers had undergone college-level education at Kasargod, a higher percentage of farmers at Kozhikode (12-25\%) and Malappuram (38$42 \%$ ) had completed school and attended college.

The source of income and employment significantly $(P<0.05)$ influenced technology adoption. The most influential factors were laborers and Malappuram FAM (Table 1). At Kasargod, activities related to fisheries such as fishing and fish marketing formed the main source of livelihood of 55-71\% mussel farmers; $16-18 \%$ of farmers were laborers and 6-12\% were engaged in other skilled work such as tailoring, trade, and driving. At Kozhikode, $82-100 \%$ of the farmers earned income from fisheries-related activities, and $18 \%$ of farmers were laborers. Contrary to this, at Malappuram, only $20-26 \%$ of the farmers depended on fisheries for their livelihood because most of farmers (51-70\%) were laborers. Coir making formed an additional source of income of 2 and $4 \%$ of farmers at Kasargod and Malappuram, respectively. Notably, at Kasargod, $6-15 \%$ and at Malappuram, $24 \%$ of farmers had only mussel farming as a source of income.

\section{Farming Methods}

The basic method of farming developed and promoted by CMFRI in India is by constructing trestles and suspending the seeded ropes from the horizontal platform (Fig. 4). However, there

TABLE 1. Demographic profile of mussel farmers (farm wise) in three districts of Kerala.$^{\text {a }}$

\begin{tabular}{|c|c|c|c|c|c|c|c|c|c|}
\hline \multirow[b]{2}{*}{ Profile } & & \multicolumn{3}{|c|}{ Kasargod } & \multicolumn{2}{|c|}{ Kozhikode } & \multicolumn{2}{|c|}{ Malappuram } & \multirow[b]{2}{*}{$\chi^{2}$} \\
\hline & & IND & FAM & SHG & IND & FAM & IND & FAM & \\
\hline \multirow[t]{4}{*}{ Age } & $<30$ & 11 & 20 & 21 & 0 & 0 & 13 & 5 & 8.6 \\
\hline & $30-50$ & 67 & 40 & 64 & 86 & 50 & 74 & 77 & 4.0 \\
\hline & $>50$ & 22 & 40 & 15 & 14 & 50 & 13 & 18 & 9.9 \\
\hline & $\chi^{2}$ & 0.1 & 5.9 & 3.9 & 3.4 & 6.2 & 1.6 & 1.5 & 22.5 \\
\hline \multirow[t]{4}{*}{ Education } & Nil & 11 & 17 & 14 & 0 & 8 & 9 & 5 & 4.1 \\
\hline & School & 78 & 79 & 77 & 75 & 80 & 49 & 56 & 5.2 \\
\hline & College & 10 & 4 & 10 & 25 & 12 & 42 & 38 & 29.1 \\
\hline & $\chi^{2}$ & 5.7 & 2.7 & 2.0 & 2.4 & 0.3 & 17.2 & 8.0 & $38.4 *$ \\
\hline \multirow[t]{6}{*}{ Occupation } & Fishing & 55 & 71 & & 82 & 100 & 20 & 26 & 21.2 \\
\hline & Laborers & 16 & 18 & & 18 & 0 & 51 & 70 & 38.5 \\
\hline & Coir making & 2 & 0 & & 0 & 0 & 4 & 4 & 2.1 \\
\hline & Other skilled work & 12 & 6 & & 0 & 0 & 0 & 0 & 11.9 \\
\hline & Mussel farming & 15 & 6 & & 0 & 0 & 24 & 0 & 12.7 \\
\hline & $\chi^{2}$ & 12.4 & 2.8 & & 7.8 & 10.5 & 25.2 & 27.8 & $86.4 *$ \\
\hline
\end{tabular}

a All values are in percentages; chi-square $\left(\chi^{2}\right)$ values which are significant $(P<0.05)$ are shown with asterisk. 


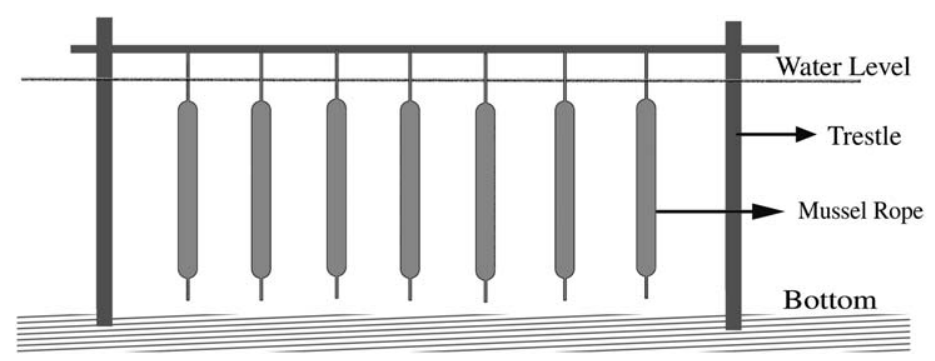

FIGURE 4. Diagrammatic representation of vertical trestle farming in areas with more than $1.5 \mathrm{~m}$ depth in Kasargod.

are some regional differences in the method of suspending the seeded ropes related to ecological conditions of the estuaries, particularly the depth of the farm site. In certain estuaries, where the depth is less than $1.5 \mathrm{~m}$, the seeded ropes are not hung vertically; rather, they are tied horizontally parallel to estuary bottom (Fig. 5). In Kozhikode and Malappuram, this method is followed, while at Kasargod, the seeded ropes are usually suspended vertically. The number of wooden poles used for farm construction also varied depending on the type of the farm.

Variations were also observed in the material used for seeding the rope. In Kasargod, the farmers used coir ropes of 22-mm diameter, and thin nylon ropes were passed through these for strengthening. At Kozhikode, the farmers use nylon rope (14-16 mm diameter), while at Malappuram, old fish nets twisted and strengthened by thin nylon rope were used as core material for seeding.

The quantity of seed used for seeding per meter of the rope or core material varied depending on the diameter of the core material. The farmers in Kasargod used nearly $3 \mathrm{~kg}$ of mussel seed for $1 \mathrm{~m}$ of seeding material, while at Kozhikode and Malappuram, the quantity used was low, 2.2 and $2.5 \mathrm{~kg}$, respectively.

\section{Economics of Farming}

A comparison of the economics of mussel farming in the three districts clearly indicated that the regional differences in farming methods influenced the total cost of production. The cost of production is much lower in Kozhikode and Malappuram, as compared to Kasargod, on account of the differences in farming methods (Table 2). The cost of seed was higher in Kasargod because most of the farmers sourced the seed from regions away from the farm site usually nearer to Kozhikode. However, in Kozhikode and Malappuram, additional expenditure was incurred by the farmers for removing the silt accumulated because of farming.

However, the productivity is higher in Kasargod and, therefore, the gross returns are also higher in spite of the lower unit sale price realized. The difference between break-even price (unit cost of production) and sale price is highest at Malappuram, followed by Kozhikode and Kasargod. The estimated CRF and IRR are higher for Malappuram and Kozhikode in comparison to Kasargod.

\section{Development of Ancillary Businesses}

The widespread adoption of mussel farming led to part-time jobs through the development

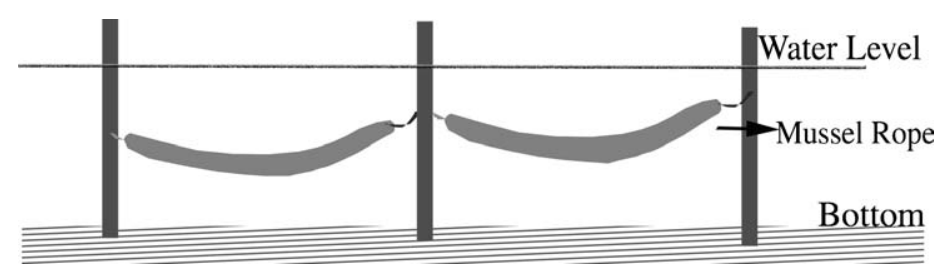

FIGURE 5. Diagrammatic representation of horizontal trestle farming in shallow $(<1 \mathrm{~m}$ ) areas (in Kozhikode [KOZ] and Malappuram [MAL] districts). 
TABLE 2. Economic comparison of commercial mussel farming (per ha) in three districts of Kerala ${ }^{\text {a }}$

\begin{tabular}{|c|c|c|c|c|c|c|c|c|c|}
\hline \multirow[b]{2}{*}{ Cost description (units) } & \multicolumn{3}{|c|}{ Kasargod } & \multicolumn{3}{|c|}{ Kozhikode } & \multicolumn{3}{|c|}{ Malappuram } \\
\hline & $\begin{array}{l}\text { Quantity/ } \\
\text { ha }\end{array}$ & $\begin{array}{c}\$ / \\
\text { unit }\end{array}$ & Value & $\begin{array}{l}\text { Quantity/ } \\
\text { ha }\end{array}$ & $\begin{array}{c}\$ / \\
\text { unit }\end{array}$ & Value & $\begin{array}{l}\text { Quantity/ } \\
\text { ha }\end{array}$ & $\begin{array}{l}\$ / \\
\text { unit }\end{array}$ & Value \\
\hline \multicolumn{10}{|l|}{ Capital investment (fixed assets) } \\
\hline Bamboo poles (number) & 7895 & 1.39 & 10,974 & 5755 & 1.39 & 8000 & 5755 & 1.39 & 8000 \\
\hline Rope for tying $(\mathrm{kg})$ & 2963 & 2.00 & 5926 & & & 0 & & & 0 \\
\hline Rope for seeding ( $\mathrm{kg}$ ) & 49,882 & 0.11 & 5487 & 1846 & 1.90 & 3508 & 15,873 & 0.11 & 1746 \\
\hline Canoe and work shed & & & 5487 & & & 1587 & & & 1587 \\
\hline Total capital investment & & & 27,874 & & & 13,095 & & & 11,333 \\
\hline Annual fixed costs & & & 18,118 & & & 8512 & & & 7367 \\
\hline \multicolumn{10}{|l|}{ Operating costs } \\
\hline Minor implements & & & 22 & & & 22 & & & 22 \\
\hline $\begin{array}{l}\text { Labor for trestle construction } \\
\text { (labor-days) }\end{array}$ & 741 & 3.7 & 2743 & 282 & 4.5 & 1270 & 282 & 4.5 & 1270 \\
\hline Biodegradable cotton netting (m) & 52,583 & 0.12 & 6310 & 15,212 & 0.12 & 1825 & 15,212 & 0.12 & 1825 \\
\hline Mussel seed $(\mathrm{kg})$ & $1,39,285$ & 0.13 & 18,107 & 34,921 & 0.07 & 2444 & 39,683 & 0.07 & 2778 \\
\hline Labor for seeding (labor-days) & 5389 & 1.12 & 6036 & 1417 & 1.12 & 1587 & 1417 & 1.12 & 1587 \\
\hline $\begin{array}{l}\text { Farm maintenance (removing } \\
\text { sediment) (labor-days) }\end{array}$ & & & 0 & 1764 & 4.5 & 7937 & 1764 & 4.5 & 7937 \\
\hline Labor for harvesting (labor-days) & 2966 & 3.7 & 10,974 & 705 & 4.5 & 3175 & 705 & 4.5 & 3175 \\
\hline Total operating costs & & & 44,192 & & & 18,260 & & & 18,594 \\
\hline Total cost of production $(\mathrm{B}+\mathrm{C})$ & & & 62,310 & & & 26,772 & & & 25,960 \\
\hline Annual yield (tonnes/ha) & & & 617 & & & 257 & & & 286 \\
\hline Sale price (USD/tonne) & & & 178 & & & 211 & & & 222 \\
\hline Gross returns & & & 109,739 & & & 54,286 & & & 63,492 \\
\hline Net operating income (G-C) & & & 65,547 & & & 36,025 & & & 44,898 \\
\hline Net cash return $(G-D)$ & & & 47,429 & & & 27,513 & & & 37,532 \\
\hline $\begin{array}{l}\text { Break-even price - (D/E) } \\
\quad \text { (USD/tonne) }\end{array}$ & & & 101 & & & 104 & & & 91 \\
\hline Capital recovery factor & & & 1.7 & & & 2.1 & & & 3.3 \\
\hline Rate of return & & & 190.0 & & & 230.0 & & & 350.0 \\
\hline
\end{tabular}

a All amounts in \$US (1 \$US = 45 INR; 2006 conversion rate). Assumptions: interest on working capital, 15\%; expected life of bamboo poles and ropes, $2 \mathrm{yr}$; expected life of canoe and work shed, 2 yr; yield differs location wise based on vertical/horizontal farming practice.

of several ancillary industries servicing the mussel farms in Kasargod, Kozhikode, and Malappuram (Table 3).

The mussel seed required for farming was supplied by mussel fishers from 13 main collection centers along the Kerala coast. During the period 2005-2006, approximately 1799 tonnes of mussel seed valued at \$US0.226 million were collected using 18,783 labor-days and supplied to mussel farmers. Although most mussel farmers themselves attended to the farming activities, they also hired other villagers for seeding, farm construction, and harvesting. For seeding of mussels, 12,995 labor-days valued at \$US0.22 million (as wages) have been created in the villages. Another outcome is the growth of mussel markets in the state. It is estimated that for transportation of seed to farm sites, 368 labor-days were used and for transporting harvested mussel from farm sites to the 14 nearby mussel markets, 2432 labor-days (valued at $\$ \mathrm{US} 13,000$ ) were used.

Several small business enterprises which supply other inputs for farming have also been established. Coir ropes spun at five centers in and around Kasargod were used for seeding by mussel farmers of Kasargod. Nylon rope, bamboo poles, and other materials used by mussel farmers were supplied by traders. Approximately 600 tonnes of coir rope worth \$US66,000, cotton cloth worth $\$ \mathrm{US} 68,000$, and nylon thread worth \$US71,000 were used as inputs in the industry. 
TABLE 3. Ancillary industries and employment generation in the three districts of North Kerala as a part of mussel farming.

\begin{tabular}{llrrrr}
\hline & District & Mussel seed collection & Mussel seeding & Harvests & Total \\
\hline Estimated labor-days & Kasargod & 17,991 & 12,354 & 2249 & 32,594 \\
& Kozhikode & 293 & 237 & 63 & 593 \\
& Malappuram & 499 & 404 & 120 & 1023 \\
& Total & 18,783 & 12,995 & 2432 & 34,210 \\
Estimated value & Kasargod & 220 & 218 & - & 438 \\
(\$US thousands) & Kozhikode & 2 & 2 & - & 4 \\
& Malappuram & 4 & 3 & - & 6 \\
& Total & 226 & 222 & - & 448 \\
\hline
\end{tabular}

\section{Public Funding and Subsidies}

The local cooperative bank NMGB of Kasargod has extended loans up to \$US5500 each for IND and FAM farms since 2003 and recently for SHGs. The bank charges an interest of 9.5$10 \%$, and repayment period is $5 \mathrm{yr}$. The loans are disbursed within 6 mo of submission of the application. The farmers also get a subsidy up to a maximum of $\$$ US2750 (50\%). However, farmers are eligible for subsidy only once. During the period 2003-2006, the bank has extended loans worth \$US0.16 million to mussel farmers. The number of SHGs who have availed loans has increased from 18 in 2002-2003 to 180 groups in 2005-2006. The technology promoter, ADAK, provided subsidy worth USD 223/farmer in
Kozhikode district during 2002-2006. The village Panchayats, particularly in Malappuram district, also funded mussel farmers through their national development schemes, besides organizing training programs.

\section{Empowerment of Women}

In Kasargod, $87.5 \%$ of the SHG farms were owned by women and through the SHG, more than 2000 women directly had partnership in mussel farms. However, men owned 69 and $71 \%$ of the IND and FAM farms in Kasargod and 61 and $64 \%$ at Kozhikode. In contrast, in Malappuram, 90.5 and $81.5 \%$ of the IND and FAM farms, respectively, were owned by women (Fig. 6).

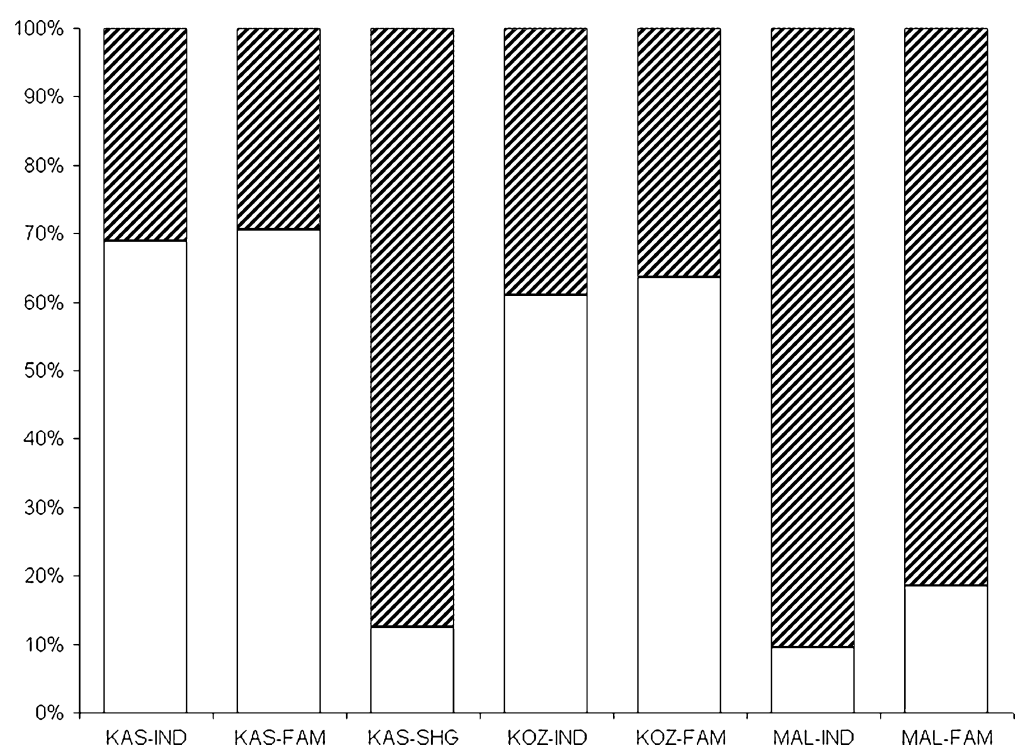

FIGURE 6. Gender-wise ownership of different types of mussel farms in Kasargod (KAS), Kozhikode (KOZ), and Malappuram (MAL) districts. Hatched bar indicates women owned and plain bars are men owned. 
One of the important outcomes of mussel farming in Kerala is the empowerment of women. Through the formation of SHG, women in the villages were able to avail financial support from banks and the local administration. Their skill as good finance managers excelled, and they were able to win the trust of the bank officials. More than 2000 women are active members of SHGs in Kasargod. The frequent discussions and self-evaluations helped them to identify their shortfalls and improve their performance each year. Although the male members of the family help them initially in preparing the project and to communicate with the banks, in due course, women became independent and were able to manage money and time very efficiently. The profit was used for meeting their commitments, like children's education, medical expenses, repayment of personal loans, and so forth. Even in the IND and FAM farms, women were the main decision makers, especially in FAM-owned farms. The overall impact was improvement in leadership and managerial skills of women and emergence of team spirit within villages.

It was observed that almost all activities such as transactions with banks, purchase of material and farm construction, seeding and stocking, harvesting and postharvest were mostly shared by both men and women of a household. Purchase of farm material and construction of farm was done mostly by men in all the three districts or with support from women members. However, seeding of mussels was mostly done by women $(89,94$, and $72 \%$ of the farmers at Kasargod, Kozhikode, and Malappuram, respectively). Similarly, activities related to harvesting such as cleaning and declumping were also done mainly by women.

\section{Discussion}

The present estimate of farmed mussel production from India indicates that it has risen to one among the top 10 mussel farming countries in Asia. The growth of mussel farming in Kerala in recent years has been phenomenal, with the number of estuarine mussel farms increasing exponentially in Kasargod, Kozhikode, and Malappuram districts. The productivity is not as high as that obtained in the sea (1000 tonnes/ha in Singapore; Chou and Lee 1997).

Among the three types of mussel farms developed, IND farms, followed by SHG farms, showed the maximum growth. Individual and group aspirations coupled with the availability of credit have played a key role in this transformation. SHGs in India are promoted by national and state government and nongovernmental organizations. These are voluntary groups engaged in collective saving and economic and thrift activities for the purpose of securing credit. The 1990s saw a proliferation of women SHGs across India, particularly in the South (Mohindra 2003). These groups were designed not only as a strategy for poverty alleviation but also to increase women's access to resources and their power in household decision making (Sundram 2001). SHGs appear poised for spearheading further growth in mussel farming in the State.

The adoption curves of mussel farming in Kerala is such that there were only a few adopters in the first two to three seasons, which were followed by an increasing rate of adoption in the subsequent years. Factors which influenced the technology diffusion are several, and it is evident that there have been network externalities in the technology adoption in Kerala, almost similar to that observed by Goolsbee and Klenow (2002) who found that people were more likely to buy their first home computers when those around them owned computers. The successful farming of mussels by setting up small units in the estuary adjacent to their homesteads motivated the villagers to adopt and own mussel farms. The strong interpersonal communication between the villagers helped to spread the technology.

In the present study, a key demographic character like age could not be significantly related to technology adoption of mussel farming. Rogers and Stanfield (1968) also did not find any consistent relationship between age and innovativeness. Some other studies like that of Adesina and Baidu-Forson (1995) and Comer et al. (1999) have found no relationship between age and technology adoption of innovative practices in agriculture. On the other hand, education and 
occupation of the respondents significantly influenced the technology adoption process in mussel farming. Rubas (2004), who did a metaanalysis regarding the universality of the factors affecting technology adoption, found age to be a weakly negative universal and education weakly positive universal. The present study clearly establishes the fact that literacy and education have played a key role in the adoption of mussel farming practice in Kerala. When compared to other maritime states in India, Kerala has one of the highest physical quality of life indices, spurred mainly by the high literacy rates from the early twentieth century (Ramachandran 1996).

Rogers and Stanfield (1968) have also indicated the compatibility of the innovation to the region to be positively related to rate of adoption, and in the case of mussel farming, this is a positive factor in Kasargod, Kozhikode, and Malappuram districts. The flexibility of the working hours and the proximity to their homesteads have encouraged more women to adopt the technology. Most of the technology adoptees were those engaged in fishing and other menial jobs (laborers), who had time to spare. Other income-generating opportunities for women in the coastal areas of Kasargod, Kozhikode, and Malappuram districts are low compared to that of Central Kerala where several fisheries-related activities, like fish drying, shrimp peeling, cleaning and processing in seafood-processing plants, are available (Sathiadhas et al. 2005). Added to this is the "achievement motivation" (Rogers and Stanfield 1968). Most of the farmers, especially women, had a satisfaction of achievement. Income from their own enterprise boosted their morale, and the new found economic independence prompted them to continue mussel farming every year. Besides, farmers in Kozhikode and Malappuram innovated the technology to suit the ecological conditions in their estuaries confirming that relative advantage of the innovation is positively related to the rate of adoption (Rogers and Stanfield 1968).

The majority of IND and FAM farm owners in Malappuram district were women in contrast to Kozhikode district where the majority were men. This can be mainly attributed to the differences in the source of financial assistance between the two districts. In Malappuram, financial assistance was mainly provided through the Panchayat development schemes which were oriented toward women entrepreneurship, while at Kozhikode, the ADAK was the main promoter of the technology which did not specifically have any gender bias. The SHG-owned farms in Kasargod were also dominated by women because SHGs were also women-oriented poverty alleviation schemes promoted by the government (Mohindra 2003). There were however no differences in the economics of farm operations between that of men and women.

Mussel farming has emerged as one of the main sources of income to the respondents almost on par with other main sources of income. The fact that it is a seasonal activity makes mussel farming secondary, although the profit earned is considerable as indicated by the economic analysis. One of the reasons for the sustained growth of mussel farming is the profitability of the technology. Being a new technology, the demonstration of mussel farming in Kasargod, Kozhikode, and Malappuram proved the relative advantage of the innovation, and those who were willing to take risk adopted the technology first. Aversion to risk has been considered as a factor influencing technology adoption (Rubas 2004). The harvests made by the early adopters helped to remove the fear of uncertainty regarding the technology motivating the hesitant group also to adopt the technology. The lag in technology adoption in the neighboring villages even after two to three crops indicated the deep-rooted "risk aversion" attitude widely prevalent among technology adopters.

The credit assistance provided by developmental agencies has definitely created a diffusion path in Kasargod, Kozhikode, and Malappuram. In Kasargod, the financial backing by the NMGB was stimulated further by the prompt repayment of the loans availed by the farmers. Feder et al. (1985) found that credit constraints can be a problem for small farms in developing countries and that it can actually impede adoption. The subsidies provided by the government agencies served to attract villagers 
to the mussel farming technology, and these first-time adopters continued the farming activity even after cessation of the subsidy after the first year. Obviously, it is the profitability and creditworthiness of mussel farming technology that have driven the adoption process in Kerala. Although a new technological venture in the state, mussel farming has very effectively diffused and has become a part of the socioeconomic profile of the coastal parts particularly of Kasargod district.

The meta-analysis of Rubas (2004) indicated that adoption does not occur in the same way everywhere, and she further infers that just because a technology is enthusiastically adopted in one area does not mean that it will be adopted with such vigor elsewhere. Although mussel farming began making an impact in Kasargod as early as in 1996-1997, it failed to make a beginning in the southern districts even though there was wide publicity to these achievements through mass media. At Kozhikode and Malappuram, the diffusion rates are low compared to Kasargod, which is probably related to the late date of startup. However, the potential for further development seems to be bright at Malappuram because the water body is extensive and can accommodate more farms and the villagers are convinced about the technology. However, at Kozhikode, the hydrodynamic features such as low water current, silting, and the shallowness of the estuary will limit the progress of the technology.

The successful adoption of mussel farming by coastal fishers in Kerala is the result of a combination of factors, chiefly, the availability of water bodies suitable for estuarine farming of mussels, high rate of literacy and education, the proximity of major mussel markets and high degree of mussel consumption in the area, and a unique synergy between technology developers, promoters, and credit advancers. As far as the technology is concerned, profitability positively relates to adoption, and risk aversion initially leads to partial or low-intensity adoption. This development scenario can work as a role model for other states and developing nations where similar hydrological, social, and market environment exists.

\section{Acknowledgments}

The authors are grateful to the Director, CMFRI, Cochin, for facilities and encouragement. They are thankful to V.G. Surendranathan for coordinating the data collection and to the Green Mussel Farmers Society for cooperation. They are also obliged to E. Vivekanandan, R. Sathiadhas, and K. Vijayakumaran for critical reading of the article and to two anonymous reviewers for critical comments, which greatly helped to improve the article.

\section{Literature Cited}

Adesina, A. A. and J. Baidu-Forson. 1995. Farmers perception and adoption of new agricultural technology: evidence from Analysis in Burkina Faso and Guinea, West Africa. Agricultural Economics 13:1-9.

Appukuttan, K. K. 1980. Culture of brown mussel Perna indica at Vizhinjam. Marine Fisheries Information Service T \& E Series 16:11-13.

Appukuttan, K. K., V. Kripa, T. S. Velayudhan, K. S. Mohamed, A. C. C. Victor, P. S. Kuriakose, P. Laxmilatha, and P. Muthiah. 2000. Bivalve mariculture in India - a success story in coastal ecosystem development. APAARI Publication:2000/1. Asia Pacific Association of Agricultural Research Institutions, FAO, Bangkok, Thailand.

Appukuttan, K. K., K. S. Mohamed, V. Kripa, P. K. Asokan, M. K. Anil, G. Sashikumar, T. S. Velayudhan, P. Laxmilatha, K. P. S. Koya, P. Radhakrishnan, M. Joseph, P. S. Alloycious, V. G. Surendranathan, M. P. Sivadasan, D. Nagaraja, J. Sharma, and M. S. Naik. 2001. Survey of green mussel seed resources along Kerala and Karnataka coasts. Marine Fisheries Information Service T \& E Series 168:12-19.

Asokan, P. K., V. P. Vipinkumar, K. K. Appukuttan, V. G. Surendranathan, and M. P. Sivadasan. 2001. Mussel culture in backwaters of Kasargod district, Kerala. Marine Fisheries Information Service T \& E Series 169:9-11.

Chou, R. and H. B. Lee. 1997. Commercial marine fish farming in Singapore. Aquaculture Research 28:767-776.

Comer, S., E. Ekanem, S. Muhammad, S. P. Singh, and F. Tegene. 1999. Sustainable and conventional farmers. A comparison of socio-economic characteristics, attitudes and beliefs. Journal of Sustainable Agriculture 15:29-45.

FAO (Food and Agriculture Organization). 2003. FAO fisheries department. Fishery information data and statistics unit. FISHSTAT Plus, universal software for fishery statistical time series version 2.30. FAO, Rome, Italy.

Feder, G., R. E. Just, and D. Zilberman. 1985. Adoption of agricultural innovations in developing countries: 
a survey. Economic Development and Cultural Change 33:255-298.

Goolsbee, A. and P. J. Klenow. 2002. Evidence on learning and network externalities in the diffusion of home computers. Journal of Law and Economics 45:317-343.

Kripa, V., K. K. Appukuttan, T. S. Velayudhan, K. S. Mohamed, P. S. Alloycious, P. Radhakrishnan, M. Joseph, and J. Sharma. 2004. Oyster farming a rural development program in Kerala. Marine Fisheries Information Service T \& E Series 180:1-6.

Kuriakose, P. S. 1980. Open sea raft culture of green mussel at Calicut. Bulletin Central Marine Fisheries Research Institute 29:33-38.

Mohamed, K. S., C. Muthiah, D. Nagaraja, and G. S. Kumar. 1998. Initiation of marine mussel culture activities in Dakshina Kannada district, Karnataka. Marine Fisheries Information Service T \& E Series 155:10-15.

Mohindra, K. S. 2003. A report on women self help groups (SHGs) in Kerala state, India: a public health perspective. FCRSS/IRSC report. Université de Montréal, Montreal, Canada.

Natarajan, P., R. Thangavelu, A. D. Gandhi, P. Poovannan, L. Jayasankaran, and A. A. K. Basha. 1997. Mussel culture experiments in Ennore estuary, Chennai. Marine Fisheries Information Service T \& E Series 148:1-4.

Qasim, S. Z., A. H. Parulekar, S. N. Harkantra, Z. A. Ansari, and A. Nair. 1977. Aquaculture of green mussel Mytilus viridis L. Cultivation on ropes from floating rafts. Indian Journal of Marine Sciences 4:189-197.

Rajagopal, S., V. P. Venugopalan, K. V. K. Nair, G. Van derVelde, H. A. Jenner, and C. den Hartog. 1998. Reproduction, growth rate and culture potential of the green mussel Perna viridis (L) in Edayar backwaters, east coast of India. Aquaculture 162:187-202.

Ramachandran, V. K. 1996. On Kerala's development achievements. Pages 308-361 in J. Dreze and A. Sen, editors. Indian development: selected regional perspectives. Oxford University Press, New Delhi, India.

Rangarajan, K. and K. A. Narasimham. 1980. Mussel farming on the east coast of India. Bulletin Central Marine Fisheries Research Institute 29:39-41.
Rivonker, C. U., Z. A. Ansari, and A. H. Parulekar. 1993. Cultivation of green mussel, Perna viridis L. on a floating raft in an estuary along the west coast of India. Aquaculture 112:47-56.

Rogers, E. M. and J. D. Stanfield. 1968. Adoption and diffusion of new products: emerging generalizations and hypotheses. Pages 227-250 in M. B. Frank, W. K. Charles, and A. P. Edgar, editors. Applications of the science in marketing. John Wiley and Sons, New York, New York, USA.

Rubas, D. 2004. Technology adoption: who is likely to adopt and how does the timing affect the benefits? $\mathrm{PhD}$ thesis. Texas A\&M University, Texas, USA.

Sasikumar, G., C. Muthiah, D. Nagaraja, B. Sridhara, and G. S. Bhat. 2000. Mussel culture in the Mulky estuary, Dakshina Kannada district, Karnataka during 1997-99. Marine Fisheries Information Service T \& E Series 164:14-18.

Sathiadhas, R., F. Hassan, and Y. J. Raj. 2005. Empowerment of women involved in clam fisheries of Kerala - a case study. Indian Journal of Social Research 46:39-48.

Sokal, R. R. and F. G. Rohlf. 1995. Biometry. W. H. Freeman \& Co, New York, New York, USA.

Sreenivasan, P. V., R. Thangavelu, and P. Poovannan. 1996. Coleroon Estuary, Tamil Nadu - a potential area for edible oyster and green mussel culture. Marine Fisheries Information Service T \& E Series 142:11-13.

Sundram, I. S. 2001. Self help groups. Challenges and opportunities. Social Welfare July 18-19.

Velayudhan, T. S., V. Kripa, K. K. Appukuttan, K. S. Mohamed, and P. Laxmilatha. 2000. Feasibility of integrated bivalve farming in an estuarine system of Central Kerala, India. Pages 209-215 in B. Tiensongrasmee, M. Tedengren, P. Jarayabhand, N. Tandavanitj, A. Popongviwat, A. Nujsawat, and S. Soisodsri, editors. Mollusk research in Asia. Thailand Research Fund, Bangkok, Thailand.

Vipinkumar, V. P., P. K. Asokan, and K. K. Appukuttan. 2001. Mussel farming by women self help groups in Kasargod district. A case study. Marine Fisheries Information Service T \& E Series 169:4-6. 